Supplementary information for

\title{
A Fireproof, Lightweight, Polymer-Polymer Solid-State Electrolyte for Safe Lithium Batteries
}

Yi Cui ${ }^{1, \#}$, Jiayu Wan ${ }^{1, \#}$, Yusheng Ye ${ }^{1, \#}$, Kai Liu ${ }^{1}$, Lien-Yang Chou ${ }^{1}$, Yi Cui ${ }^{1,2, *}$

${ }^{1}$ Department of Materials Science and Engineering, Stanford University, Stanford, California 94305, United States

${ }^{2}$ Stanford Institute for Materials and Energy Sciences, SLAC National Accelerator Laboratory, 2575 Sand Hill Road, Menlo Park, California 94025, United States

*Email: yicui@stanford.edu

\#These authors contributed equally to this work. 


\section{Methods}

Chemicals and materials. N-methyl pyrrolidone (NMP, Sigma Aldrich), dimethylacetamide (DMAC, Sigma Aldrich), PEO (MW = 300,000, Sigma Aldrich), LiTFSI (Solvay), acetonitrile (anhydrous, Sigma Aldrich), 4,4'-Oxydianiline (ODA, Sigma Aldrich), pyromellitic dianhydride (PMDA, Sigma Aldrich), 4,4'-[1,4-Phenylenebis(oxy)bis[3-(trifluoromethyl)aniline] (6FAPB, Sigma Aldrich), decabromodiphenyl ethane (DBDPE, Sigma Aldrich), ethanol (EtOH, Sigma Aldrich), LFP powders (MTI), carbon black (Sigma Aldrich), Li foil (Sigma Aldrich).

Preparation of PI/DBDPE film. $1 \mathrm{~g}$ of NMP and $9 \mathrm{~g}$ of DMAC was mixed in a $20-\mathrm{mL}$ vial under magnetic stirring for $10 \mathrm{~min}$. Then ODA $(0.159 \mathrm{~g}), 6$ FAPB $(0.341 \mathrm{~g})$, and PMDA $(0.556 \mathrm{~g})$ was added in the mixed solution sequentially. It was noted that the time interval of adding the three samples should be more than $30 \mathrm{~min}$. Then $0.452 \mathrm{~g}$ of DBDPE was added in the solution and was kept under magnetic stirring for 12 hours to obtain PAA/DBDPE solution. Doctor blading was performed to coat the as-obtained solution on the glass. The gap depth varied from 3 mil to 10 mil was used to control the thickness of the film. After coating, the film was kept on the glass for $\sim 60$ min to guarantee that NMP and DMAC were fully evaporated, followed by the rinsing of the film with DMAC and EtOH (v:v = 1:1) for 15 min for pores creation. The as obtained PAA/DBDPE nanoporous film was dried for $\sim 60 \mathrm{~min}$ to fully evaporate the DMAC and EtOH. The dried nano-porous PAA/DBDPE film was imidized in a box furnace at air atmosphere to obtain PI/DBDPE film. The temperature ramping program was set as: (1) Ramp up from room temperature (RT) to $100{ }^{\circ} \mathrm{C}$ at $3{ }^{\circ} \mathrm{C}$ $\min ^{-1}$; (2) Keep at $100{ }^{\circ} \mathrm{C}$ for $30 \mathrm{~min}$; (3) Ramp up to $200{ }^{\circ} \mathrm{C}$ at $3{ }^{\circ} \mathrm{C} \min ^{-1}$; (4) Keep at $200{ }^{\circ} \mathrm{C}$ for $30 \mathrm{~min}$; (5) Ramp up to $300{ }^{\circ} \mathrm{C}$ at $3{ }^{\circ} \mathrm{C} \mathrm{min}^{-1}$; (6) Keep at $300{ }^{\circ} \mathrm{C}$ for $30 \mathrm{~min}$; (7) Cool down to RT in furnace.

Preparation of SSE. PEO was mixed with LiTFSI and acetonitrile using a Thinky mixer (Thinky Cooperation). The EO to Li ratio was 10:1. Pure PEO/LiTFSI films were prepared by doctor blade casting followed by drying in a vacuum oven at $60{ }^{\circ} \mathrm{C}$ for $24 \mathrm{~h}$ and baking in an Ar-filled glove box at $70{ }^{\circ} \mathrm{C}$ for at least $48 \mathrm{~h}$. PI/DBDPE/PEO/LiTFSI solid electrolytes were obtained in a facile two-step process. First, as-prepared PEO/LiTFSI/acetonitrile solution drops were spun at 4,000 r.p.m. with porous PI film. The as-prepared $\mathrm{PI} / \mathrm{DBDPE} / \mathrm{PEO} / \mathrm{LiTFSI}$ film was then baked at $180{ }^{\circ} \mathrm{C}$ under vacuum to ensure the full 
infiltration of PEO/LiTFSI in the nanopores. The excess PEO/LiTFSI was scraped off at $150{ }^{\circ} \mathrm{C}$ on a hot plate. The PI/DBDPE/PEO/LiTFSI film then underwent the same drying process as the regular PEO/LiTFSI film.

Preparation of other battery components. LFP powders, PEO/LiTFSI and carbon black $(\mathrm{w}: \mathrm{w}: \mathrm{w}=60: 25: 15)$ were mixed in acetonitrile using a Thinky mixer. The LFP active material loading was $1.5 \mathrm{mg} \mathrm{cm} \mathrm{cm}^{-2}$. The slurry was then bladed on $\mathrm{Al}$ foil to render uniform coating, which was further dried in vacuum oven at $60{ }^{\circ} \mathrm{C}$ for at least $48 \mathrm{~h}$. Coin cells (2032 type, MTI) were made either with $\mathrm{Li} / \mathrm{SSE} / \mathrm{Li}$ or LFP/SSE/Li-type cells. LTO powders, PEO/LiTFSI and carbon black $(\mathrm{w}: \mathrm{w}: \mathrm{w}=60: 25: 15)$ were mixed in acetonitrile using a Thinky mixer. The slurry was then doctor blade casted on $\mathrm{Cu}$ foil. Pouch cells were made with LFP/SSE/LTO-type cells.

Materials characterizations. SEM images were obtained with a FEI XL30 Sirion SEM. Mechanical tests were undertaken with a TA instrument Q800 DMA.

Electrochemical characterizations. Long-term cycling of symmetrical Li-Li cells were conducted with a symmetrical $\mathrm{Li} / \mathrm{SSE} / \mathrm{Li}$ structure in coin cells (2032 type). Rate capability tests were carried out in LFP/SSE/Li-type coin cells (2032 type) with Bio-logic VMP3 and LAND systems. All temperature-controlled experiments were tested inside an environmental chamber (BTU-133, ESPEC North America) using a high-precision thermometer $\left( \pm 0.1^{\circ} \mathrm{C}\right)$.

Flame test of SSEs. All of the SSEs were tailored to be with the same size $(2 \mathrm{~cm} \times 0.5 \mathrm{~cm})$ and similar thickness $(\sim 50 \mu \mathrm{m})$.

Thermal abuse test of pouch cells. The pouch cells were made with LFP/SSE/LTO-type cells. EC/DEC/PE, PEO/LiTFSI, and PI/DBDPE/PEO/LiTFSI were used as the SSEs here.

\section{Discussions}

Cross-sectional SEM images of the filled PI/DBDPE/PEO/LiTFSI film (Figure S4) demonstrated the complete infiltration of PEO/ LiTFSI in the nanopores of PI/DBDPE film. To measure the ionic conductivity of PI/DBDPE/PEO/LiTFSI film, we intentionally prepared relatively thick films (Figure S5) for a more accurate measurement of the intrinsic ionic conductivity of the composite SSE. We tested the impedance of the PI/DBDPE/PEO/LiTFSI solid-state electrolyte at $30{ }^{\circ} \mathrm{C}$ and $60{ }^{\circ} \mathrm{C}$, and the Nyquist plot of a typical cell is shown in Figure S6. The ionic conductivity (calculated by equation below) of the composite SSE film 
was slightly lower than that of PEO/LiTFSI thin film at these temperatures. Specifically, the PI/DBDPE composite SSE showed ionic conductivity of $6.7 \times 10^{-6} \mathrm{~S} / \mathrm{cm}$ and $6.3 \times 10^{-5} \mathrm{~S} / \mathrm{cm}$ at $30{ }^{\circ} \mathrm{C}, 60{ }^{\circ} \mathrm{C}$, respectively, whereas the PEO/LiTFSI thin film showed conductivity of $5.4 \times 10^{-5} \mathrm{~S} / \mathrm{cm}$ and $3.2 \times 10^{-4} \mathrm{~S} / \mathrm{cm}$ at $30{ }^{\circ} \mathrm{C}$ and $60{ }^{\circ} \mathrm{C}$ correspondingly. The values are very close, considering the porosity of the host is around $50 \%$.

Although the ionic conductivity of PEO/LiTFSI in the nanopores of PI/DBDPE film is not the highest amongst other organic/inorganic solid-state electrolytes (usually $1 \sim 3 \times 10^{-4}$ $\mathrm{S} / \mathrm{cm}$ at $30{ }^{\circ} \mathrm{C}$ ), the impedance of the whole PI/DBDPE/PEO/LiTFSI film can be extremely low due to the very thin thickness $(\sim 10 \mu \mathrm{m})$. For example, at $30{ }^{\circ} \mathrm{C}$, the overall ionic resistance of a $10 \mu \mathrm{m} \mathrm{PI/DBDPE/PEO/LiTFSI} \mathrm{film} \mathrm{is} \mathrm{about} 150 \mathrm{ohm}$, comparable to the state-of-the-art organic/inorganic solid-state electrolytes of 70-200 ohm (assuming a typical thickness of $200 \mu \mathrm{m})$. Furthermore, the PI/DBDPE is a host structure in our case, it could potentially provide better ionic conductivity with highly ionic conductive polymer or composite electrolyte fillers.

The DBDPE additive in the composite SSE layer is sufficient to render the entire cell fire retardant. We have tested the flammability of a conventional polymer electrolyte (PEO/LiTFSI) cell (Figure S9a), and our SSE (PI/DBDPE/PEO/LiTFSI) cell (Figure S9b) after removing the flammable pouches. The active cathode and anode materials used for demonstration here were LFP and LTO without DBDPE, respectively. As shown in Figure S9a, PEO/LiTFSI cell caught fire immediately as the lighter approached and then combusted violently. However, PI/DBDPE/PEO/LiTFSI cell exhibited excellent flame-retarding ability (Figure S9b), which demonstrated that the integration of DBDPE in electrolyte was enough to suppress the combustion of the whole cell. 

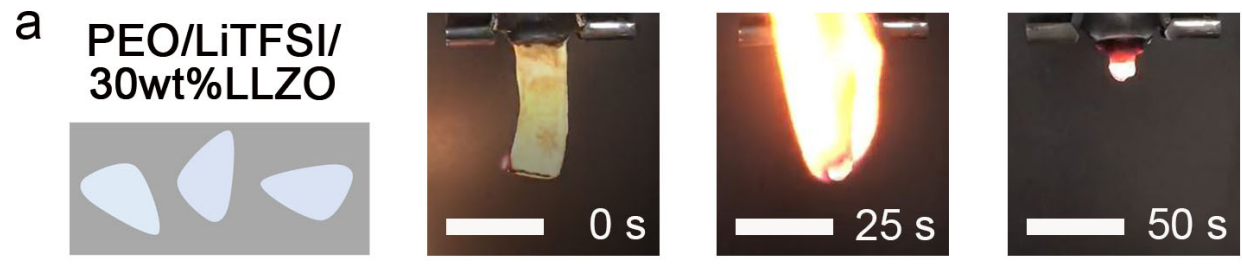

b PEO/LITFSI/ $30 \mathrm{wt} \% \mathrm{Al}_{2} \mathrm{O}_{3}$
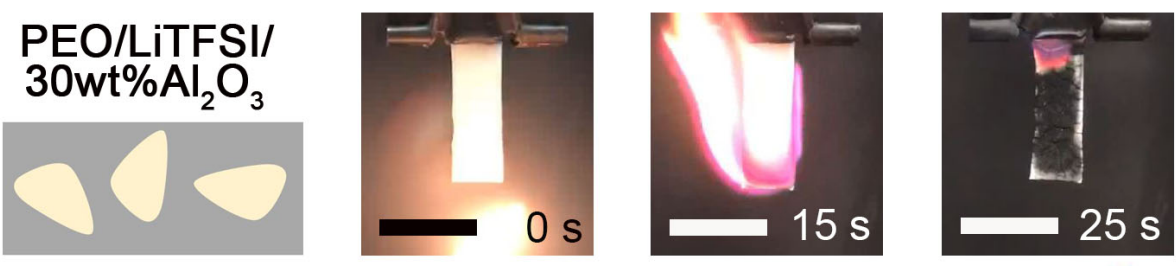

Figure S1. Flame tests of a) PEO/LiTFSI/30wt\%LLZO and b) PEO/LiTFSI/30wt $\% \mathrm{Al}_{2} \mathrm{O}_{3}$. Scale bars, $1 \mathrm{~cm}$. (first figures on the left of both $\mathrm{a}$ and $\mathrm{b}$ are schematics) 
a

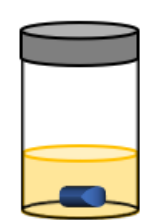

b

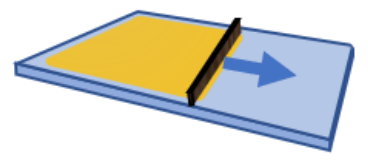

$\mathrm{c}$

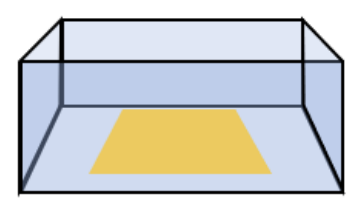

d

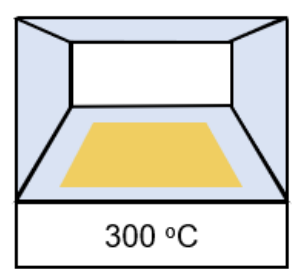

Figure S2. Schematic illustration of the synthetic procedure of PI/DBDPE nanoporous film. a) The reactants were kept under magnetic stirring to obtain PAA/DBDPE solution. b) Doctor balding process. c) The PAA/DBDPE film was emerged in DMAC/EtOH solution to create the porous structure. d) The porous PAA/DBDPE film was heated at $300{ }^{\circ} \mathrm{C}$ to form porous PI/DBDPE film. 


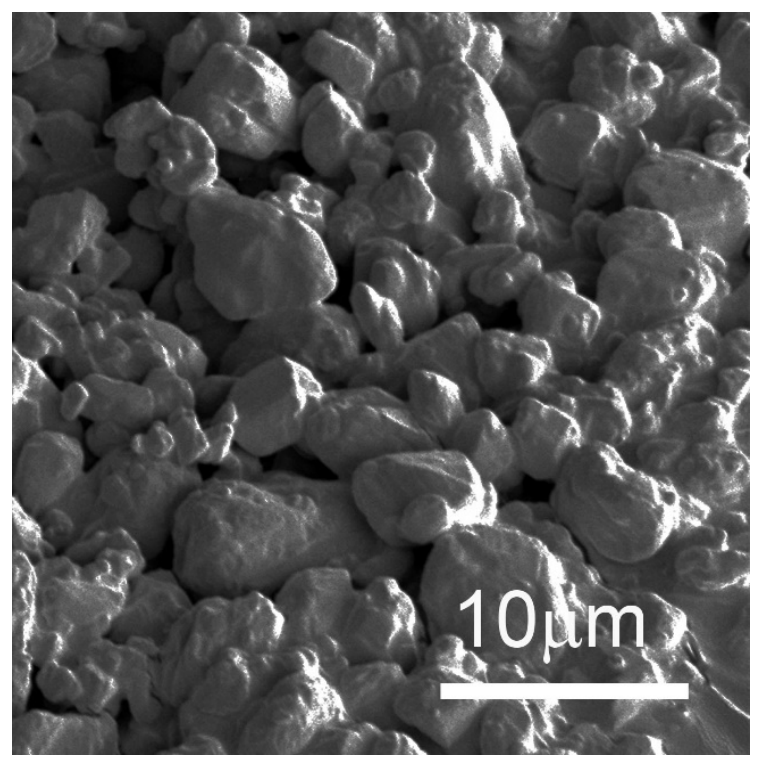

Figure S3. SEM image of DBDPE particles. 


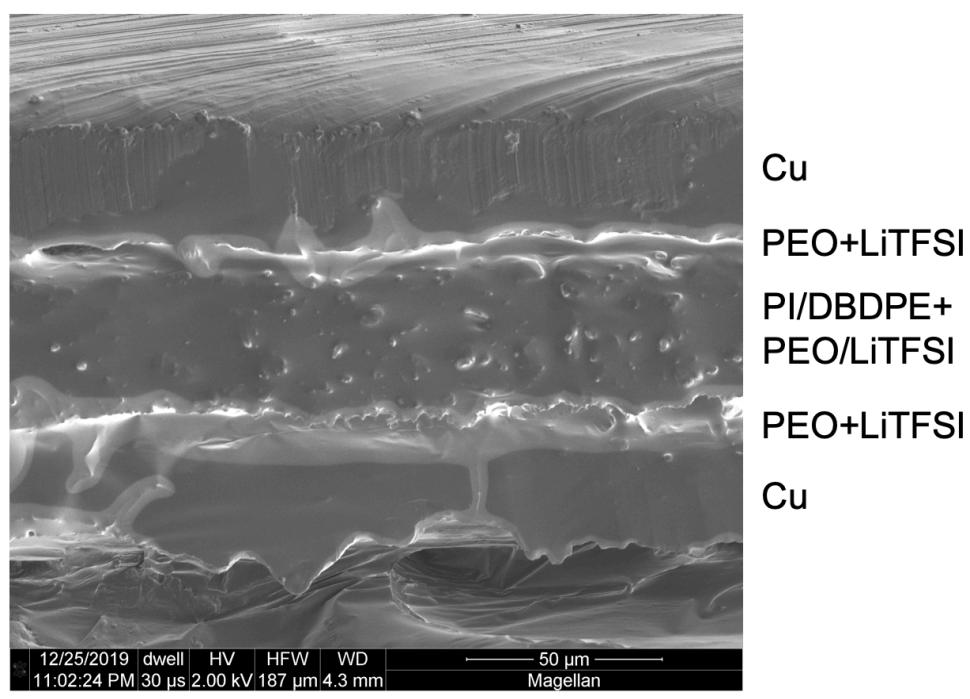

Figure S4. Cross-section image of thick PI/DBDPE/PEO/LiTFSI for ionic conductivity measurement (with residual PEO/LiTFSI on both sides), demonstrated the PEO/LiTFSI can fully infiltrate to the porous structure. 

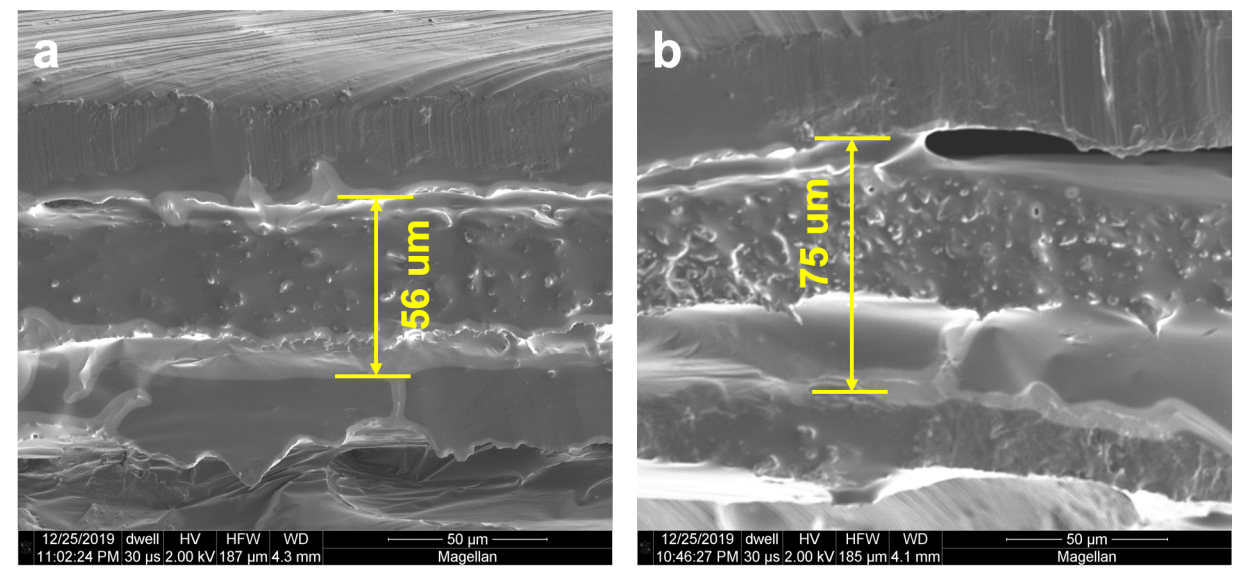

Figure S5. Cross-sectional SEM images of thick PI/DBDPE/PEO/LiTFSI between two $\mathrm{Cu}$ foils for ionic conductivity measurement. 


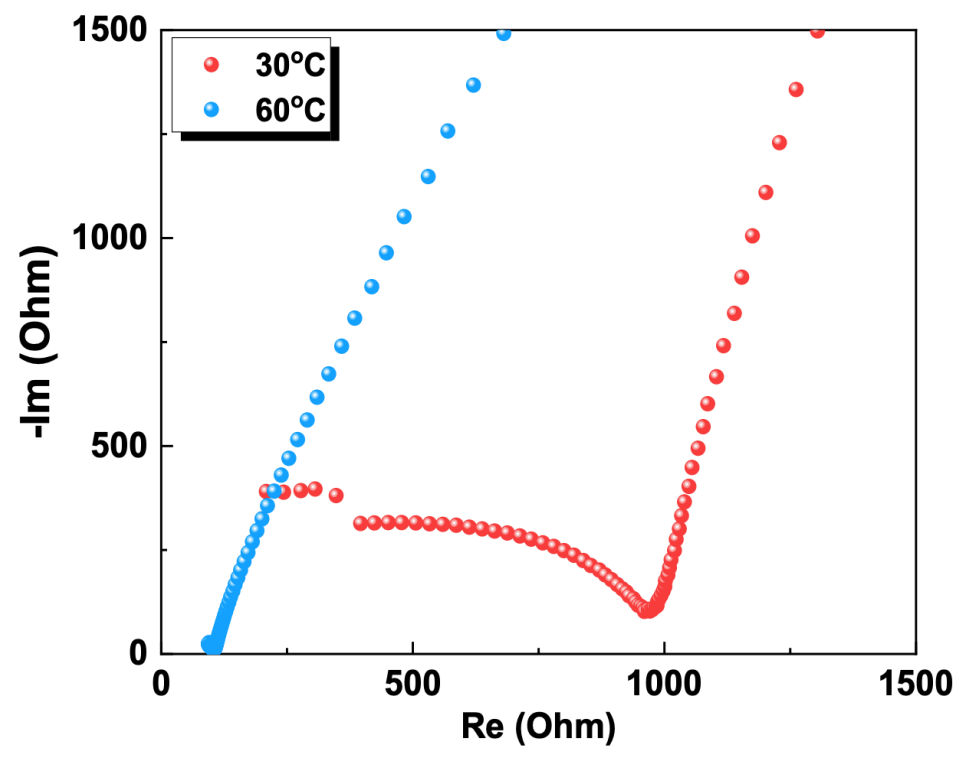

Figure S6. Nyquist plot of a typical thick $(\sim 65 \mu \mathrm{m})$ composite SSE after EIS test at $30{ }^{\circ} \mathrm{C}$ and $60^{\circ} \mathrm{C}$, respectively. 

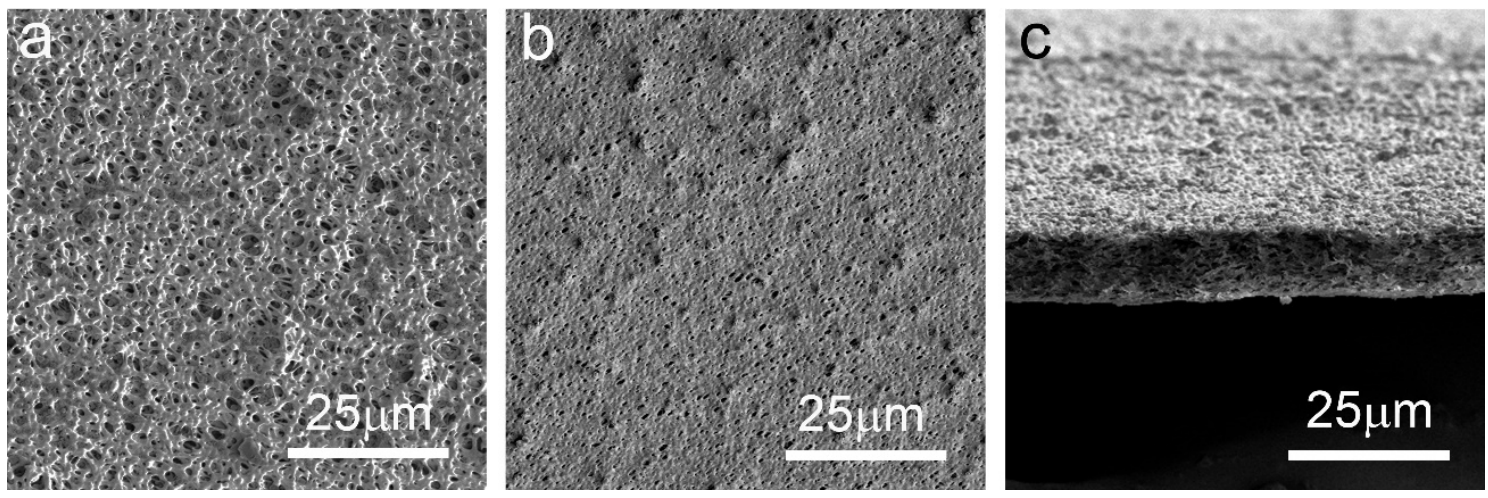

Figure S7. SEM images of the PI film's surface, which are the surface morphology a)facing air and b) facing glass in the doctor blading process, respectively. c) Cross-section SEM image of a typical PI film. 


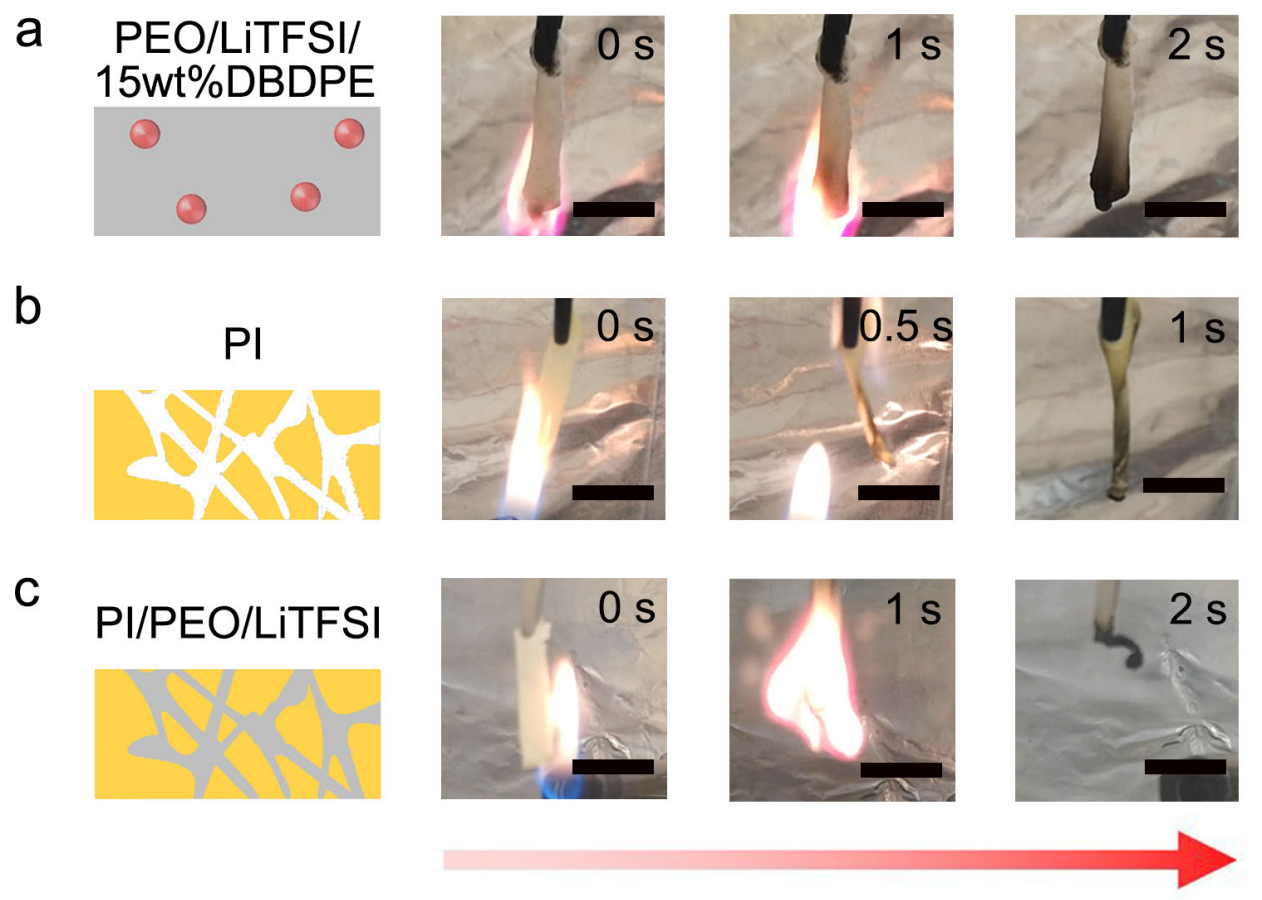

Figure S8. Flame tests of a) PEO/LiTFSI/15wt\%DBDPE, b) PI film, and c) PI/PEO/LiTFSI film. Scale bars, $1 \mathrm{~cm}$. 
a

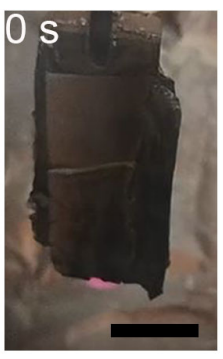

b $\mathrm{Os}$

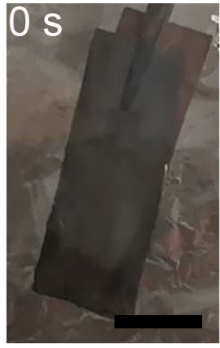

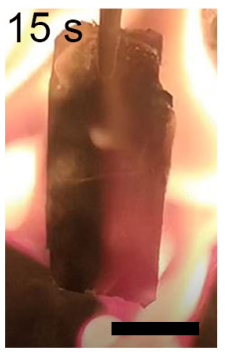

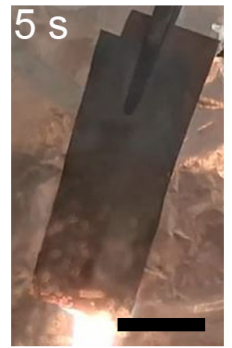

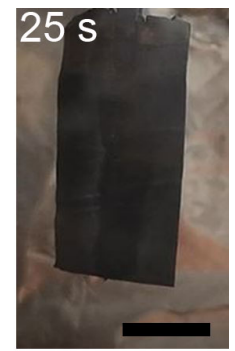

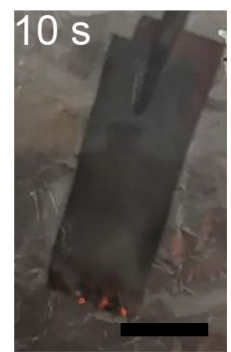

Figure S9. Flame tests of a) PEO/LiTFSI cell and b) PI/DBDPE/PEO/LiTFSI cell after removing the flammable pouch with LFP and LTO electrodes. Scale bars, $2 \mathrm{~cm}$. 
Video S1. Flame test of PEO/LiTFSI/30wt\%LLZO.

Video S2. Flame test of PEO/LiTFSI/30wt $\% \mathrm{Al}_{2} \mathrm{O}_{3}$.

Video S3. Flame test of PEO/LiTFSI/15wt\%DBDPE.

Video S4. Flame test of PEO/LiTFSI.

Video S5. Flame test of PI/DBDPE.

Video S6. Flame test of PI/DBDPE/PEO/LiTFSI.

Video S7. Flame test of PI.

Video S8. Flame test of PI/PEO/LiTFSI.

Video S9. Flame abuse test of pouch cell with conventional liquid electrolyte/polymer separator (EC/DEC/PE). The cathode and anode materials used for demonstration here were LFP and LTO, respectively.

Video S10. Flame abuse test of pouch cell with conventional solid electrolyte (PEO/LiTFSI). The cathode and anode materials used for demonstration here were LFP and LTO, respectively.

Video S11. Flame abuse test of pouch cell with our polymer-polymer solid electrolyte (PI/DBDPE/PEO/LiTFSI). The cathode and anode materials used for demonstration here were LFP and LTO, respectively. 